\title{
SCIENCE AND SYNDROMES
}

\author{
A. L. Cochrane, M.B., M.R.C.P. \\ Welsh National School of Medicine, Tuberculosis \& Chest Diseases Department, \\ Sully Hospital, Sully, Glam.
}

Medical Research Council Epidemiological Research Unit.

Physicians appear to have a special love for syndromes. They enjoy diagnosing, demonstrating and discussing them. The syndrome seems to have a snob value denied the simple symptom. The reasons for this are possibly concerned with the cult of the rare, or even with that widespread human weakness of "namedropping". Some of the names associated with syndromes do trip off the tongue in an attractive way. The reason for their popularity is unlikely to be scientific as no one seems to have pointed out how closely a medical syndrome in its description and investigation typifies the scientific method in its simplest form. This, as every one knows, consists of, first, the idea, then the translation of the idea into a hypothesis, and finally the critical testing of the hypothesis. A syndrome fits this pattern perfectly. The idea connects two medical phenomena (signs and/or symptoms) that have not previously been connected; the hypothesis in these cases is simply a restatement of the idea, i.e., that the two phenomena occur more frequently together than can be acoounted for by chance association and the testing of the hypothesis is, theoretically, relatively straightforward-or so it would seem. The physician's interest unfortunately seems to stop short at discussion and does not extend, in all cases, to detailed investigation. Many syndromes have been very fully investigated, but the technique used in some investigations of some aspects of some syndromes are lamentable.

One example from a distinguished medical journal will, it is hoped, suffice to point the moral without the need of mentioning the authors. The paper was concerned with one aspect of the "Marfan" syndrome. It was designed to prove that the use of an index (the ratio of the length to the breadth of the metacarpals) enabled one to differentiate clearly between cases of Marfan's syndrome and "normals". A table was published showing a clear-cut difference between the values of the indices for the two groups. Fig. 1 is based on this table, and shows how wide the gap was between the two distributions. Their group of 'normals' was not described in detal. The odd truncated distribution of the values for the 'normals' makes one rather suspiciouss. Such distributions are very rare in unselected biological material, and this one suggests thist the authors in their hurry to validate theor index had forgotten how 'selected' hospigl material is and how dangerous comparisons made with such material may be. One woutd imagine that it would be self-evident that those coming into hospital with a particular disease are not usually typical of all people suffeigigig from that disease, and that those, withoutca particular disease, in hospital, are not typicas of all those, in and outside hospital, lacking the disease. But a great deal of clinical researoh has been ruined by neglect of these simge facts and research into syndromes has suffered more than most.

It was impossible in this particular case to check exactly on this work. It would have required a group of people of the same age and sex as the Marfan group chosen at random from those living in the same area as thizit group. We did, however, possess a set of X-rays of the hands of a random sample of men on the Rhonidda Fach, aged 35-44, amongst whom there were no cases of the Marfan syndrome. Mrs. Joan Kilpatrick measured the same index on those X-rays and the results are shown $\mathrm{In}$ Fig. 2. This demonstrates clearly that the index is 'normally' distributed and that the truncated normal distribution was probably an artefact introduced by 'selection'. It is abso clear that the distribution of our normals overlaps that of the Marfans so that it is unlikedy that the index clearly separates them frem
normals.

It would be possible, but rather malicious, to quote other examples of this kind, but moral is surely clear. Although there is great clinical interest in the syndromes, this does 


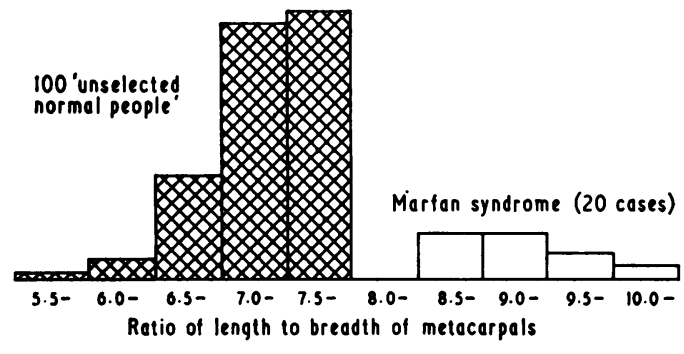

Fig. 1.-Distribution of the Marfan index in 100 'Unselected Normal People' and 20 cases of the Marfan Syndrome.

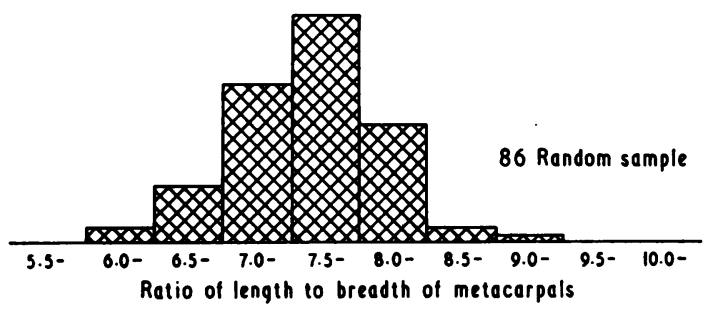

FIG. 2.-Distribution of the Marfan index in a random sample of Rhondda Fach males aged $35-44$.

not produce enough energy to find suitable controls when testing the underlying hypotheses. It is more constructive to consider an example where a hypothesis about a syndrome was adequately investigated.

Our first example is the Paterson-Kelly (Plummer-Vinson) syndrome. Although in the original description this was described as a symptom (dysphagia) in middle-aged women, most text-books now treat it as a syndrome in which the dysphagia is associated with irondeficiency anæmia. There have been many publications purporting to support this association (Moersch and Conner, 1926; Witts, 1931; Jacobs \& Kilpatrick, 1964). These were nearly all based on groups of hospital patients with dysphagia compared with other groups of hospital patients without dysphagia. One of the more extraordinary groups of hospital 'controls' was a group of patients suffering from carcinoma (Wynder and Fryer, 1958).

This hypothesis of association can, of course, only be adequately tested by comparing an unselected group of people with this particular type of dysphagia with a group of the same age and sex, chosen at random from people without dysphagia living in the same area as the former. This feat has finally been carried

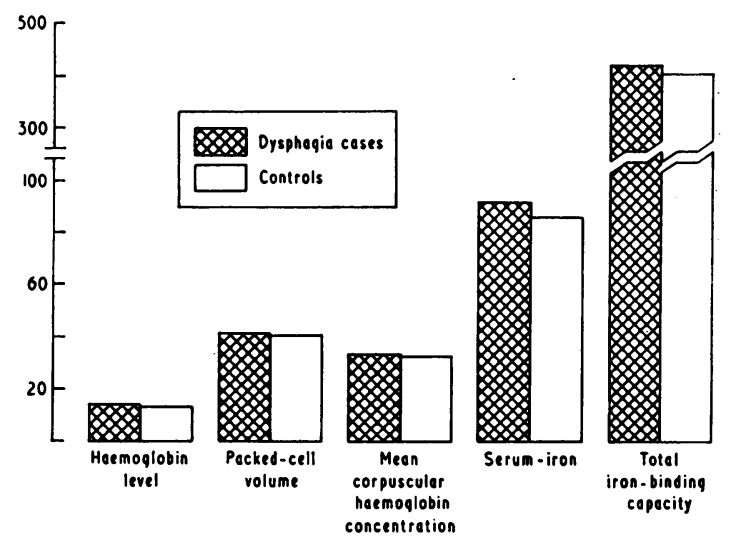

Fig. 3.- Mean levels of haematological variates in women with dysphagia and in their controls.

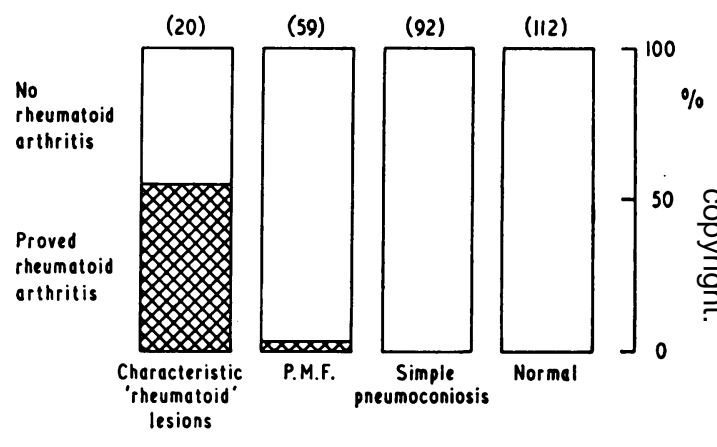

FIG. 4.-Prevalence of rheumatoid arthritis among Rhondda Fach miners and ex-miners according to type of X-ray.

out by Elwood and his colleagues (Elwood, Jacobs, Pitman and Entwistle, 1964) using a part of the population of the Rhondda Fach and to everyone's surprise no difference as regards anæmia was found between the two groups. Fig. 3 is based on their findings. No evidence in support of the existence of the syndrome could be found. Although this finding needs confirming in another area, it looks as if Paterson and Kelly's day as a syndrome is over; they must be content with being a symptom in the future.

The last example is the happiest one. Dr. Caplan described his syndrome in Cardiff (Caplan, 1953). It consisted of an association between rheumatoid arthritis and a particular appearance in the chest X-rays of coalminers. Very soon after the publication of the association it was critically tested by Miall and his 
colleagues using all the miners and ex-miners in the Rhondda Fach (Miall and others, 1953), who established conclusively that the association was real. Fig. 4 is based on their findings. It is clearly much more satisfactory if the syndrome can be tested in its cradle so that the literature does not get cluttered up with syndromes suggesting unreal associations.

Probably the best advice to give those who are nursing new syndromes in the back of their minds is to arrange a critical test with the help of an epidemiologist before anything is published at all.

\section{REFERENCES}

Caplan, A. (1953): Certain Unusual Radiological Appearances in the Chests of Coal Miners
Suffering from Rheumatoid Arthritis. Thorax, 29.

Elwood, P. C., Jacobs, A., Pitman, R. G., 腐 ENTWISTLE, C. C. (1964): Epidemiology of the Paterson Kelly Syndrome. Lancet, i, 716.

JACOBS, A., and Kilpatrick, G. S. (1964): 居e Paterson Kelly Syndrome. Brit. med. J., ii, 79.

Miall, W. E., Caplan, A., Cochrane, A. L., KofPATRICK, G. S., and OldhaM, P. D. (1953): 有 Epidemiological Study of Rheumatoid Arthrmis Associated with Oharacteristic Chest X-R appearances in Coalworkers. Brit. med. J., ii, 1231 .

MOERSCH, H. J., and CONNER, H. M. (1926): Hysterical Dysphagia. Arch. Otolaryng., 4, 112,

WITTS, L. J. (1931): The Syndrome of Glossitis, Dysphagia and Anaemia. Guy's Hos. Rep., 81, 193 . WYNDER, E. L. and FrYer, J. H. (1958): Etiologic Considerations of Plummer Vinson (Pattersion Kelly) Syndrome. Ann. intern. Med., 49, 1106. 